\title{
Optimizing Innovation with the Lean and Digitize Innovation Process
}

\author{
Bernardo Nicoletti
}

\author{
"It must be remembered that there is nothing more difficult") \\ to plan, more doubtful of success, nor more dangerous to \\ management than the creation of a new system. For the \\ initiator has the enmity of all who would profit by the \\ preservation of the old institution and merely the lukewarm \\ defense in those who gain by the new ones.
}

Nicolo Machiavelli (1469-1527)

Philosopher and playwright

\begin{abstract}
Actionable knowledge to improve innovation and bring value to the customers and organizations is essential in today's economy. In the past, there have attempts to apply Lean Thinking and Six Sigma to the innovation processes, with mixed results. The aim of this article is discuss how to improve innovation processes using the Lean and Digitize Innovation process, which integrates digitization into the Lean Six Sigma method. Through the redesign of innovation processes and their automation, the process aims to add value to customers, improve effectiveness, eliminate waste, minimize operating costs, and reduce time-to-market. This new method is characterized by seven stages, or "the 7 Ds" (define, discover, design, develop, digitize, deploy, and diffusion), with 29 steps. This article describes the Lean and Digitize Innovation process and presents cases where the approach has been successful in helping innovation processes from start to end: from the definition of the value for the customers up to the implementation of a prototype and engineering of the delivery processes.
\end{abstract}

\section{Introduction}

Innovation is crucial to the success of any business. Far too many organizations spend the bulk of their efforts on improving production, finance, and marketing and not enough efforts on improving innovation. Innovation is becoming increasingly more important as the demands of the global economy increase. Organizations need to be agile, current, and smart in order to face the challenges of the changing global economy (Oza \& Abrahamsson, 2009; Wilson \& Doz, 2011).

Lean Innovation represents the systematic interpretation of Lean Thinking principles relative to innovation in its different forms. There are few systematic implementations of Lean Thinking in innovation management, contrary to what has happened in the production world (Liker, 2003; Schuh et al., 2009). High uncertainties of processes, novelty, and complexity indicate special requirements for the implementation of Lean
Thinking in innovation processes. They require holistic rethinking for the implementation of Lean Thinking.

This article focuses on the lean processes, describes their phases, and shows how to use and benefit from the combination of Lean Six Sigma with digitization towards a powerful lean innovation method for improving processes. The method aims to add value to customers, improve effectiveness, eliminate waste, minimize operating costs, and reduce time-to-market through the redesign of the innovation processes and their automation. This approach is increasingly necessary for global success and is an important pre-requisite for success in the lean application of innovation processes.

The Lean and Digitize Innovation process represents the systematic interpretation of Lean Thinking principles regarding to the different types of innovation and development, while also taking into account the possibilities of automation. 


\title{
Optimizing Innovation with the Lean and Digitize Innovation Process
}

\author{
Bernardo Nicoletti
}

\section{Review of Literature on Improving Innovation Processes}

First, we examine the literature that examines issues connected with the implementation of Lean Innovation. Lean management and innovation are two driving forces of today's business success. However, with fundamentally different concepts, some aspects of lean management may negatively affect an organization's ability to be successful with certain types of innovations.

Subramanyam, Srinivasan, and Prabaharan (2011) applied Lean and Six Sigma to new product development activities. To make the system effective and deliver the design at the shortest time to market with good quality, it is necessary to optimize material cost and design time. Subramanyam and colleagues dealt with an approach associated with the optimization of the abovementioned problems with the strategy of Six Sigma.

Shuh, Lenders, and Hieber (2009) introduced Lean Innovation and described the core findings of their survey on Lean Innovation at the Laboratory for Machine Tools and Production Engineering WZL at RWTH Aachen University. Their paper focused on the value system, described its elements, and showed how to use and benefit from the value system towards powerful Lean Innovation. The value system is one core element of Lean Innovation, which is the basis for the value stream design in innovation and development projects. The value system defines, structures, and prioritizes "values" adaptively for one specific innovation project. All relevant stakeholders in the innovation process, such as external and internal customers, define the values considering the organization's strategy and culture. This activity represents the basis for a consequent value-oriented alignment of projects and processes in innovation.

Hoppmann and colleagues (2011) studied the implementation of Lean Product Development . They surveyed 113 product development departments of international organizations. Based on the insights gained from the testing of the hypotheses and the available empirical data, they defined a Lean Innovation Roadmap. They used a novel, two-step methodology called Adjusted Past Implementation. The resulting roadmap for implementing Lean Product Development consists of four major phases and shows the introduction of the eleven Lean Product Development components in the form of eleven overlapping implementation streams. For each of the components, Hoppmann and colleagues defined four detailed characteristics and depicted the time for implementing these characteristics on the roadmap, giving an idea of when to introduce the elements of Lean Product Development relative to each other. For organizations intending to implement a Lean Product Development system, the Lean Innovation Roadmap can serve as a guideline for learning and continuously improving their organizations.

Gerhard and colleagues (2012) investigated the impact of lean principles in innovation-intense organizations, that is, companies of the automotive and machinery industries as well as in research facilities. They suggested that the implementation of lean principles creates positive effects in technology development, for instance, in reducing the development time and increasing the development efficiency. They found that out of the existing lean principles, the two principles of "avoidance of waste" and "flow", have the highest influence on the improvement of development activities

Browning and Sanders (2012) pointed out that, when operations are novel and complex - as in product development, research, information technology, and many other kinds of projects - cutting out the waste turns out to be much more challenging. To understand the impact of lean in an environment characterized by extreme novelty and complexity, these authors drew on their experiences with a number of processes, and in particular Lockheed Martin's lean implementation for the F-22 fighter aircraft. Their find $\neg$ ings lead to a path that executives and managers can follow to become lean without compromising innova $\neg$ tion.

Chen and Taylor (2009) presented five propositions based on a comparison between the lean culture, lean design, lean supply chain management, and lean human resource management with the characteristics and contributing factors of different types of innovations. These authors discussed different strategies for an organization to achieve the balance and maintain lean and innovation at the same time. They analyzed advantages, disadvantages, and suitable situations for each strategy.

Nepal (2011) extended the new product development literature by presenting a case study of a Lean Product Development transformation framework implemented at a manufacturing firm in the United States. In a departure from typical Lean Product Development methods, they integrated the design structure matrix and the cause and effect matrix into the lean transformation framework. In this way, they allowed analysis of the un- 


\section{Optimizing Innovation with the Lean and Digitize Innovation Process} Bernardo Nicoletti

derlying complexity of a product development system, and thus facilitating determination of the root causes of wasteful reworks. They discussed several strategies to transform the current product development process into a lean process. In order to support the recommended changes in the new product development processes, they recommended a two-phase improvement plan, a new organizational structure roadmap, and a human resources plan. The results of the Lean Product Development show a $32 \%$ reduction in product development cycle time due to the proposed new product development process. Nepal's paper also details the lessons learned and the implications for engineering managers based on the case study presented.

For organizations to survive and thrive in today's environment, a key strategy is to leverage innovation capability through an effective process of converting unmet customer needs into successful innovations, thereby creating value for customers, the organizations, and other stakeholders. Welo, Olsen, and Gudem (2012) demonstrated how Lean Thinking could become a precompetitive factor in product innovation through its focus on customer value. The goal of this paper was to determine the applicability of user-centered methodologies in generating inputs that ultimately lead to differentiated innovations. Welo and colleagues presented an office chair case study that implied that, although user-focus is necessary, it will not inevitably lead to novel products, because users are engrossed with past and present.

Lean Thinking can even be used to drive general innovation in organizations (Byrne et al., 2007; Hoerl \& Gerdner, 2010). Lean Thinking frees up an organization's resources - people, space, time, and money - such that more resources can be allocated to innovation projects. Another consequence of the application of lean is the support for a fundamental culture shift. Morale will go up when people in an organization start dealing with the complexity in the business. Lean Thinking eliminates or streamlines the processes and products that waste time, that frustrate customers, and that do not add value, thus freeing up the time for people to start thinking about what should come next (Cross, 2012, 2013).

Lean transformation and innovation have both been touted as strategies that are essential to the long-term survival of organizations. The question of whether the two approaches can be used simultaneously remains unanswered. Srinivasan (2010) attempted to derive a theory of lean systems of innovation that combines the notions of lean enterprise trans $\neg$ formation with that of innovation. The descriptive understanding of Rockwell Collins, as developed in their paper, draws on publicly available material to support the identification of the key elements of a strategic system of innovation. Srinivasan's analysis highlights the successful use of technology scanning, internal $R \& D$, and open innovation within the innovation system at Rockwell Collins. Furthermore, the existence of a shared value proposition, a strong organizational culture that recognized and rewarded innovation, and the requisite organizational infrastructure serve as key enablers to designing a strategic system of innovation that is reflective of lean enterprise thinking.

Fichman, Dos Santos, and Zheng (2014) adopted a particularly broad conceptualization of digital innovation that allows for a variety of teaching styles and topical emphases for the information system core class. This conceptualization includes three types of innovation (i.e., process, product, and business model innovation), and four stages for the overall innovation process (i.e., discovery, development, diffusion, and impact). Based on this conceptualization, these authors examined the implications of adopting digital innovation as a fundamental and powerful concept in teaching organizations

None of the papers examined in this literature review analyzed the actual process of Lean Innovation projects in depth. Thus, the purpose of this article is to introduce the Lean and Digitize Innovation Process.

\section{Innovation Processes}

Innovation can be in the product or the process (Tushman \& Nadler, 1986). Innovation can also be relative to organization or to business models (Nicoletti, 2013). Breuer (2013) reports some successful examples of Lean Innovation in venturing (see also Euchner, 2013). Innovation can be classified based on the whether it is incremental or radical (Ettlie et al., 1984), or modular or architectural (Henderson \& Clark, 1990). At the heart of the innovation work is the ability to connect the strategy and tactics associated with developing a system of innovation from a macro-per $\neg$ spective, with the mechanics of effectively transitioning ideas into products, processes, organization, or business models.

Freeman and Perez (1988) define innovation as the introduction of new and improved ways of doing things at work. In an economic sense, an innovation is accomplished with the first commercial transaction involving a new or improved product, process, or organization of 


\section{Optimizing Innovation with the Lean and Digitize Innovation Process} Bernardo Nicoletti

business model. Thus, innovation is restricted to intentional attempts to bring about benefits from changes. These might include economic benefits, personal growth, increased satisfaction, improved group coherence, better organizational communication, as well as productivity and economic measures that are usually taken into consideration. The innovations of technology firms often include technological changes such as new products, production processes, the introduction of advanced manufacturing technology, as well as the introduction of new information and communication technologies (ICT).

Many models have been developed for acquiring a better understanding of the innovation process. These models have ranged from simple "pipeline" or "black box" models to complicated models. Some of them focus on consumer product innovation; others are concerned with industrial innovation. Although numerous models have been developed to describe the innovation process, no model appears to be capable of being used as a generalized model of innovation (Koskinen \& Vanharanta, 2002).

Based on observations in the Toyota Production System, Mehri (2006) illustrated some of the negative effects of the lean design process on product innovation. In particular, he underlined that the original Lean Thinking method, rather than allowing open innovation, requires engineers to follow strict flows of design. Due to a product design approach that is heavily based on benchmarking and standardization, internal innovations seem to be impossible. The Lean and Digitized Innovation process allows organizations to overcome this challenge.

\section{Research Methodology}

Essential for Lean Innovation is the definition of value for the innovation itself. Therefore, the starting point of Lean and Digitize Innovation is a systematic method to define and handle target values and requirements regarding the innovation as an enabler for a lean development process - the value system. The value system represents a framework for mapping value in a holistic, hierarchical, dynamic, and transparent way (Schuh et al., 2008).

The value system defines, structures, and prioritizes "values" adaptively for one specific innovation project. All relevant stakeholders in the innovation processes, such as external and internal customers, define the values, while considering the organization strategy and culture. It represents the basis for a consequent valueoriented alignment of innovation projects and processes. According to Gudem and colleagues (2013), maximizing customer value is a core principle in innovation, but the value definitions used tend to be based on logical reasoning rather than real-life observations. These authors, based on empirical insights concerning different stakeholders' perceptions of customer value, suggested a redefinition of the functional product value calculation in Lean Product Development. Their method integrates emotional customer value into the traditional model, which is based on minimizing operating costs and reducing time-to-market.

Lean management and innovation are two driving forces of business success. However, with fundamentally different concepts, some aspects of lean management may negatively affect an organization's capability to be successful with certain types of innovations. This article develops a process to minimize such impacts. It is based on combining Lean Six Sigma principles and tools with automation of the innovation processes. In addition, the article discuss different example where this process was successful.

Value system practices focus on market orientation of products and services. Products and services heavily rely on the supply chain process to contribute to the value system. Globalization, competition, and high cost of production influence the value system imperatives. Organizations involved in the value system are challenged with the creation of innovation. ICT can support the improvements in the performance of innovation in many organizations. There are efforts to use ICT as a tool to innovate processes, products, and services for establishing improved management practices to harness better returns on investment and customer satisfaction

\section{Results and Discussion}

Several stages compose the Lean and Digitize (short for Lean Six Sigma and Digitize) Innovation process. To be successful, Lean and Digitize Innovation must adopt a process that this article describes as "the 7 Ds: define, discover, design, develop, digitize, deploy, and diffusion. It is essential to apply this methodology and its tools in strong partnership between the sectors of the organization involved, including quality and support departments (such as ICT, finance, or operations) (Nicoletti, 2012). Stakeholders from all parties need to align in setting up and staffing the improvement project team. Perhaps more importantly, the organizations must treat the initial application of the Lean and Digit- 


\section{Optimizing Innovation with the Lean and Digitize Innovation Process}

\section{Bernardo Nicoletti}

ize Innovation process as the beginning of an iterative cycle that generates continuous improvement and leads to a change in the culture of the organizations towards Lean thinking (Womack \& Jones, 2003). A "problem" or "challenge" should not trigger process-improvement efforts. It should be a substantial part of the organizational culture.

It is important to blend process improvement and ICT technology. Based on research and experience, one can profitably use the Lean and Digitize Innovation process. In reference to Lean Innovation, Lean and Digitize Innovation can be summarized as follows. It can be divided into seven stages and 29 steps, as described below and illustrated in Figure 1. At the end of each stage are "toll gates", where the project needs to be checked by the innovation steering committee.

\section{Stage 1: Define}

In this stage, the environment is defined to set the ground for the innovation.

1. Context: identify the needs or the requests of the customers, shareholders, and employees, as well as the challenge of competitors and the degree of respect for compliance (e.g., legislation and regulations)

2. Culture: detect the culture of the organization, of the community, and of the nation in which the organization is located

3. Vision: tackle the problems of effectiveness, efficiency, economy, and quality of innovation

4. Strategy: define the possible content of innovation

5. Kick-off: launch the project during a special meeting and notify all the stakeholders

6. Governance: define how to manage the project and set up the team

7. Voice of the Customer: listen to the Voice of the Customers (VoC) associated with the potential innovation and verify it

\section{Stage 2: Discover}

In this stage, new ideas are discovered for potential development into a process, product, organization, or business model innovation.

8. Invention: the creation of something new through a organization's own creative process

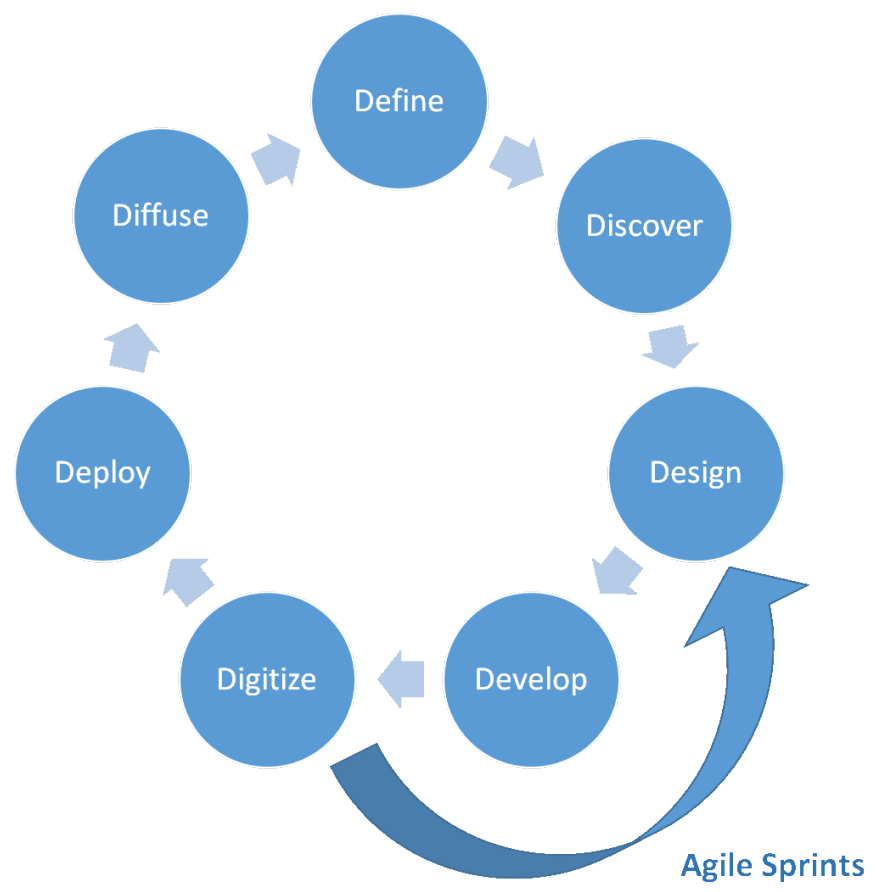

Figure 1. The Lean and Digitize Innovation process and its seven stages, or "the 7 Ds"

9. Selection: finding and evaluating an innovation to potentially develop or adopt

10. Metrics: translate the innovation and the $\mathrm{VoC}$ into Critical-to-Quality (CtQ) factors

11. As-Is: map the existing situation in terms of products, processes, organization, or business models

\section{Stage 3: Design}

In this stage, the framework and the sequence of activities are defined.

12. Lean: define how to innovate with the support of the team in workshops and meetings

13. Kaizen Plan: define the improvement intervention plan

14. Architecture Design: define the rules, policies, and process structure of the potential innovation

Stage 4: Develop

In this stage, an idea is developed into a usable innovation.

15. Build: construct the chosen solutions 


\section{Optimizing Innovation with the Lean and Digitize Innovation Process}

\section{Bernardo Nicoletti}

16. Packaging: surround the core technology with complementary products and services that together form a solution that can be effectively used for a given purpose by a target adopter

17. Configure: decide which technology features will be used, whether they will be used as is or with adaptations, how the technology will be integrated with other technologies the organization already has in place, how related organizational elements (e.g., structures, processes) will be changed, and how the organization will absorb and make use of the technology

\section{Change management: manage the changes}

\section{Stage 5: Digitize}

In this stage, the automation is applied at the highest possible level.

\section{Implementation: implement the digitized application}

20. Test: unit tests, system tests, integration tests, and user acceptance tests should all be conducted

Stage 6: Deploy

In this stage, the innovation is implemented and the ancillary activities are performed.

\section{Deploy: implement the chosen solution}

22. Document: issue the documents related to the innovation

\section{Verify: control the improvements}

24. Internal and External Benefits: assess the benefits, both external (i.e., take notice of customers, shareholders, and employees satisfaction) and internal (i.e., assess the profitability, market share, and internal improvements related to the new process)

\section{Lessons Learned: learn from the initiative}

26. Celebration: acknowledge the team's work

\section{Stage 7: Diffusion}

In this stage, it is necessary to assemble and arrange the resources necessary to i) persuade and enable a population of organizations or individuals to adopt and use the innovation and ii) to diffuse or spread it across a population of potential users.
27. Assimilation: when individuals and other units absorb the innovation into their daily routines and the work life of the firm

28. Appropriation: involves such tasks as managing intellectual property and the ecosystem of complementary products and services so that profits are protected from suppliers, customers, and imitators

29. Transformation: the technology and organization to take advantage of the new opportunities brought about by the innovation; transformations can also happen at the market and societal levels

Stages 3, 4, and 5 should be done with an Agile approach, doing several cycles, or "springs" in the Agile terminology. An Agile approach is a development method based on iterative and incremental development, where requirements and solutions evolve through collaboration between self-organizing, cross-functional teams (Socha et al., 2013). It promotes adaptive planning, evolutionary development and delivery, and a time-boxed iterative approach, and it encourages rapid and flexible responses to change. It is a conceptual framework promoting tight interactions throughout the development cycle.

Margaria and Steffen (2010) stressed the simplicity of the Agile approach. Its importance in introducing innovation in software development has been stressed (Aaen, 2008). Brown and Levison (2011) also highlighted how Agile can foster innovation. A similar concept was introduced for instructional systems development (Groves et al., 2012).

The Agile Manifesto is based on twelve principles (Beck et al., 2001). They can be customized in connection with Lean and Digitize Innovation:

1. Customer and organization satisfaction should be pursued by rapid delivery of useful innovation

2. Requirement changes should be welcomed, even late in the innovation process

3. Incremental working innovations should be delivered frequently (e.g., every few weeks rather than months)

4. Incremental working innovations are the principal measure of progress 


\section{Optimizing Innovation with the Lean and Digitize Innovation Process}

\section{Bernardo Nicoletti}

5. Development should be sustainable; the team must be able to maintain a constant pace

6. There should be close, daily cooperation between business people and the innovation team

7. In-person conversation is the best form of communication (co-location but also virtual teams)

8. Projects should be built around motivated individuals, who should be trusted

9. Continuous attention should be paid to technical excellence and good design

10. Simplicity - the art of maximizing the amount of work not done - is essential

11. Teams should be self-organizing

12. Adaptation to the changing environment is encouraged

\section{Tools}

Many tools can be used in conjunction with the process described. They can come from the tools used in Lean, Six Sigma, Agile management, and digitization. This article will not consider the latter ones, because since they are extensive and well covered in many publications. The following discussion does not consider all the possible tools that can be used but only the most appropriate.

One of the best tools for process design is Quality Function Deployment (QFD), commonly known as the House of Quality. It identifies the potential customer value of the innovation based on the customer's (be they internal or external) needs and an innovation's (normally a product) quality characteristics. The analysis through QFD is used to determine when a new innovation is useful, so excess resources are not consumed for innovation that may not be beneficial.

Another useful tool is TRIZ (a Russian acronym for Theory of Inventive Problem Solving). The requirements for innovation can be defined by introducing the TRIZ problem-solving approach in finding innovative solutions to technical problems, especially in product development processes. TRIZ is implemented to define the solutions necessary to improve these processes. The use of TRIZ is beneficial with the lean practice because it efficiently utilizes resources in the system to eliminate waste.
Yamashima, Ishida, and Mizuyama (2005) describe a new method, named the Innovative Product Development Process (IPDP). It systematically integrates QFD with TRIZ and enables the effective and systematic creation of technical innovation for new products. In IP$\mathrm{DP}$, the target products' functions and mechanisms are deployed in parallel into hierarchical structures, and the mechanism that most requires technical innovation is specified from an analysis of customers' needs by calculating a mechanism weight. Then, the technical problems to be solved are defined by considering the relationship between the specified mechanism and corresponding functions or quality characteristics. The application of TRIZ helps in developing the "technical" innovation. The technical innovation of a washing machine proved the effectiveness of IPDP.

Another important tool is prototyping, which is both a culture and a language (Kelley, 2001). Just about anything can be prototyped - a new product or service, a process, even an organization or a business model. What counts is moving the ball forward, achieving some part of a goal.

In the case of product innovations, Digital Mock Up (DMU) is a concept that allows the description of a product, usually in 3D, for its entire life cycle (Subramanyam et al., 2011). The product design, manufacturing, and support engineers work together to create and manage the DMU. One of the objectives is to have important knowledge of the innovation to replace any physical prototypes with virtual ones, using 3D computer graphics techniques. As an extension, it is frequently referred to as Digital Prototyping or Virtual Prototyping. The benefits of DMU are:

1. Reduced time-to-market by identifying potential issues earlier in the design process

2. Reduced product development costs by minimizing the number of physical prototypes that need to be built

3. Increased product quality by allowing a greater number of design alternatives to be investigated before a final one is chosen

There are several practices connected with the Agile approach, such as extreme programming from software engineering, which enables the team to work together to determine goals and shared objectives; the rational unified process from both systems and software engineering because of its iterative development methodo- 


\section{Optimizing Innovation with the Lean and Digitize Innovation Process}

\section{Bernardo Nicoletti}

logy; the focus on eliminating waste from lean manufacturing; and the daily scrum update meetings from product development. These processes enable the innovation team to adapt to changing requirements, reduce the project risk, increase the visibility of team progress, involve stakeholders and learners from the beginning of projects, and speed up the creation of value that the team makes to the business.

Innovation in organizations is important. A key to effective and efficient innovation is the ability to commercialize new products quickly and economically while leveraging the advantages of global outsourcing. The growing role of global outsourcing in innovation represents a paradigm shift that has had a large impact on innovation and commercialization, as noted by Marion and Friar (2012). They explored the use of outside innovation and commercialization resources, from contract employees to short-run manufacturers. They then synthesized their research into four areas where innovation operators could most effectively leverage outsourcing throughout the innovation continuum. Opportunities include developing strong strategic partnerships with outside vendors, using rapid prototyping resources to support agile development, using shortrun manufacturers to test products and markets before building to volume, and using expert contractors to reduce fixed personnel costs.

These tools and approaches are helpful for a lean environment because they promote effective and efficient innovation.

\section{Business Cases}

The best examples of the Lean and Digitize Innovation process have been tested and implemented in General Electric (Nicoletti, 2006). General Electric teaches innovation operators to use Lean and Digitize Innovation to respect all their processes using a few of the lesserknown lean tools (Immelt, 2012; Prokesch, 2009):

- 7-ways

- Pugh matrix

- Mock-up

- Kaizen

- 5 Why's

- Right-size machine prototyping
Business success starts with understanding the challenges the customers need to solve. It requires reams of information for answers. However, as data sources proliferate, organizations risk being overwhelmed. The Lean and Digitize Innovation process has proved particularly beneficial in these cases.

Veolia Water - the water division of Veolia Environnement, a French company that is the global leader in environmental businesses that include water, waste, and energy - use sifts through masses of information for business intelligence (Laîné, 2014). Starting in 2007, Veolia Water implemented a program to identify and manage strategic knowledge for competitive intelligence and patent services that help the organization anticipate technological developments and environmental threats and sort information from specialized sources - including databases, websites, and institutional sources and compile targeted information for its experts to analyze.

Not all of an organization's knowledge resides in databases. Each employee's knowledge is even richer, but more distributed or isolated by function. Social innovation technology inspired by Facebook but tuned for business can use employee knowledge regardless of location or role.

When automotive parts supplier Visteon assembled a cross-functional global team to develop a new concept for an automotive component, it used cloud-based social innovation applications that, in a lean and digitized way, facilitate collaboration, idea sharing, and progress tracking (Laîné, 2014).

Misra and Choudhary (2010) presented the efforts of a rug company in the direction of an innovation cycle management to ensure a development-oriented value chain. They developed a framework to examine initially the ICT intervention scenario and then how ICT can mediate in certain areas in the value chain.

\section{Conclusions and Further Research}

This article presents a Lean and Digitized Innovation process that has proved very successful in a certain number of business cases. The Lean and Digitize Innovation process is based on the application of several stages described as "the 7 Ds": define, discover, design, develop, digitize, deploy, and diffusion). These seven stages are further divided into 29 steps. The process is based on Lean Six Sigma principles but optimizes the use of ICT systems and agile methodologies to tackle the novelty and complexities in innovation processes. 


\section{Optimizing Innovation with the Lean and Digitize Innovation Process}

\section{Bernardo Nicoletti}

Improving the innovation process is the competitive advantage in innovation-intense industries, as required by today challenging times. The combination of lean and digital technologies helps in making organizations faster and more efficient than competitors, thus creating the basis for competitiveness and future success. In this context, the transfer and application of lean principles and digitization is an appropriate approach to face these challenges.

The Lean and Digitize Innovation process presented in this article has proved successful in a certain number of business cases in manufacturing companies. It would be interesting to consider its extension to service industries, where the digitized components become much more important. Campanerut and Nicoletti (2010) started some work in this direction for the Design for Six Sigma (DFSS), but additional work is necessary.

The Lean and Digitize Innovation process has demonstrated benefits in cases involving product innovation. It seems particularly important to extend its applications to innovation in processes, organizations, and business models. This extension might require modifications to make it successful.

\section{About the Author}

Bernardo Nicolletti is a Lecturer at the Master in Procurement Management at the Università di Tor Vergata in Rome, Italy. He serves as a Director in Transigma, a strategy consultancy company specialized in process improvements and digitization in financial services with assignments in Europe, USA, and the Middle East. Bernardo has worked with General Electric Capital as Program Manager of a Common Systems and later as Group Chief Technology Officer of GE Money and Acting CIO. He has also been CIO Latin America for AIG UPC. He is a frequent speaker at international conferences and author of books, papers, and blog posts (lean digitize.com), through which he describes his approaches to synthesizing Lean Six Sigma and automation.

Citation: Nicoletti, B. 2015. Optimizing Innovation with the Lean and Digitize Innovation Process. Technology Innovation Management Review, 5(3): 29-38.

http://timreview.ca/article/879

Keywords: lean innovation, agile innovation, lean six sigma, lean and digitize, innovation management, re-engineering

\section{Acknowledgements}

An earlier version of this article was presented at the 2014 International Conference on Engineering, Technology, and Innovation (ICE), which was held from June 23rd to 25th in Bergamo, Italy. The ICE conference discusses systems engineering as a socio-technical task, with a focus on design of products and services, and the entrepreneurial innovation process for its adoption in society and the economy.

\section{References}

Aaen, I. 2008. Essence: Facilitating Agile Innovation. In Agile Processes in Software Engineering and Extreme Programming, 1-10. Berlin, Germany: Springer.

Beck, K. et al. 2001. Principles behind the Agile Manifesto. Manifesto for Agile Software Development. Accessed March 1, 2015: http://agilemanifesto.org/principles.html

Breuer, H. 2013. Lean Venturing: Learning to Create New Business through Exploration, Elaboration, Evaluation, Experimentation, and Evolution. International Journal of Innovation Management, 17(3): 1-22.

http://dx.doi.org/10.1142/S1363919613400136

Brown, R., \& Levison, M. 2011. Creativity for Agile Teams. Accessed March 1, 2015:

http://agilecrossing.com/wp-content/uploads/2011/11/HandoutAgile2011.pdf

Browning, T. R., \& Sanders, N. R. 2012. Can Innovation Be Lean? California Management Review, 54(4): 5-19. http://dx.doi.org/10.1525/cmr.2012.54.4.5

Byrne, G., Lubowe, D., \& Blitz, A. 2007. Using a Lean Six Sigma Approach to Drive Innovation. Strategy \& Leadership, 35(2): 5-10. http://dx.doi.org/10.1108/10878570710734480

Campanerut, M., \& Nicoletti, B. 2010. Best Practices for DFSS in the Development of New Services: Evidence from a Multiple Case Study. The Journal of American Business Review, 16(1): 1-8.

Chen, H., \& Taylor, R. 2009. Exploring the Impact of Lean Management on Innovation Capability. In Proceedings of the 2009 International Conference on Management of Engineering \& Technology, 826-834.

Cross, B. 2012. Lean Innovation: Understanding What's Next in Today's Economy. Boca Raton, FL: CRC Press.

Cross, B. 2013. Lean Innovation - Getting to 'Next'. Ivey Business Journal, 77(3): 23-27.

Ettlie, J. E., W. P. Bridges, \& O'Keefe, R. D. 1984. Organization Strategy and Structural Differences for Radical versus Incremental Innovation. Management Science, 30: 682-695. http://dx.doi.org/10.1287/mnsc.30.6.682

Euchner, J. 2013. What Large Companies Can Learn from Start-Ups. Research Technology Management Journal, 56(4): 12-16.

Fichman, R. G., Dos Santos, B. L., \& Zheng Z. 2014. Digital Innovation as a Fundamental and Powerful Concept in the Information Systems Curriculum. MIS Quarterly, 38(2): 329-353. 


\section{Optimizing Innovation with the Lean and Digitize Innovation Process}

\section{Bernardo Nicoletti}

Freeman, C., \& Perez, C. 1988. Structural Crises of Adjustment, Business Cycles and Investment Behavior. In G. Dosi, C. Freeman, R. Nelson, G. Silverberg, \& L. Soete (Eds.), Technical Change and Economic Theory, 38-66. London, UK: Pinter Publishers.

Gerhard, D., Engel, S., Schneiner, C., \& Voigt, K. I. 2012. The Application of Lean Principles and its Effects in Technology Development. International Journal of Technology Management, 57(1/2/3): 92-109. http://dx.doi.org/10.1504/IJTM.2012.043953

Groves, A., Rickelman C., Cassarino, C., \& Hall, M. J. 2012. Are You Ready for Agile Learning Design? TD Magazine, 66(3): 46-50.

Gudem, M., Steinert, M., Welo, T., \& Leifer, L. 2013. Redefining Customer Value in Lean Product Development Design Projects. Journal of Engineering, Design and Technology, 11(1): 71-89. http://dx.doi.org/10.1108/17260531311309143

Henderson, R. M., \& Clark, K. B. 1990. Architectural Innovation: The Reconfiguration of Existing Product Technologies and the Failure of Established Firms. Administrative Science Quarterly, 35(1): 9-30. http://www.jstor.org/stable/2393549

Hoerl, R. W., \& Gerdner, M. M. 2010. Lean Six Sigma, Creativity, and Innovation. International Journal of Lean Six Sigma, 1(1): 30-38. http://dx.doi.org/10.1108/20401461011033149

Hoppmann, J., Rebentisch, E., Dombrowski, U., \& Zahn, T. 2011. A Framework for Organizing Lean Product Development. Engineering Management Journal, 23(1): 3-15.

Immelt, J. R. 2012. The CEO of General Electric on Sparking an American Manufacturing Renewal. Harvard Business Review, 90(3): 43-46.

Kelley, T. 2001. Prototyping is the Shorthand of Innovation. Design Management Journal (Former Series), 12(3): 35-42. http://dx.doi.org/10.1111/j.1948-7169.2001.tb00551.x

Koskinen, K. U., \& Vanharanta, H. 2002. The Role of Tacit Knowledge in Innovation Processes of Small Technology Companies. International Journal of Production Economics, 80(1): 57-64. http://dx.doi.org/10.1016/S0925-5273(02)00243-8

Laîné, D. 2014. Working Smarter. Compass Magazine, January 2014. Accessed March 1, 2015: http://compassmag.3ds.com/3/Cover-Story/WORKING-SMARTER

Liker, J. K. 2003. The Toyota Way. New York, NY: McGraw-Hill USA.

Margaria, T., \& Steffen, B. 2010. Simplicity as a Driver for Agile Innovation. Computer, 43(6): 90-92.

http://doi.ieeecomputersociety.org/10.1109/MC.2010.177

Marion, T. J., \& Friar, J. H. 2012. Managing Global Outsourcing to Enhance Lean Innovation. Research Technology Management, 55(5): 44-50.

http://dx.doi.org/10.5437/08956308X5505053

Mehri, D. 2006. The Darker Side of Lean: An Insider's Perspective on the Realities of the Toyota Production System. Academy of Management Perspectives, 20(2): 21-42. http://dx.doi.org/10.5465/AMP.2006.20591003

Misra, H., \& Choudhary, K. 2010. Opportunities and Challenges for ICT Mediated Innovations in Development Oriented Value Chain: The Case of Jaipur Rugs Company. Vilakshan: The XIMB Journal of Management, 7(2): 21-48.
Nepal, B. P., Yadav, O. P., \& Solanki, R. 2011. Improving the NPD Process by Applying Lean Principles: A Case Study. Engineering Management Journal, 23(1): 52-68.

Nicoletti, B. 2006. Nuovo Pignone, l'Arte di Fondere Lean Management e Six Sigma, Computerworld Italia, 6 (Dec): 1-2.

Nicoletti, B. 2013. Innovazione: Una Ricetta per la Crescita. Strategie \& Procurement, Luglio: 18-19.

Nicoletti, B. 2012. The Methodology of Lean and Digitize. Farnham, UK: Gower Press.

Oza, N., \& Abrahamsson, P. 2009. Building Blocks of Agile Innovation. Charleston, SC: Book Surge Publishing.

Prokesch, S. 2009. How GE Teaches Teams to Lead Change. Harvard Business Review, 87(1): 99-106.

Schuh, G., Lenders, M., \& Hieber, S. 2011. Lean Innovation: Introducing Value Systems to Product Development. International Journal of Innovation \& Technology Management, 8(1): 41-54. http://dx.doi.org/10.1109/PICMET.2008.4599723

Schuh, G. Lenders, M. \& Hieber, S. 2008. Lean Innovation: Introducing Value Systems to Product Development. In Proceedings of the 2008 International Conference on Management of Engineering \& Technology, 27-31.

Stevens, G. A., \& Swogger, K. 2009. Creating a Winning R\&D Culture II. Research Technology Management, 52(2): 22-28.

Socha, D., Folsom, T. C., \& Justice, J. 2013. Applying Agile Software Principles and Practices for Fast Automotive Development. In Proceedings of the FISITA 2012 World Automotive Congress, 1033-1045.

Srinivasan, J. 2010. Creating a Lean System of Innovation: The Case of Rockwell Collins. International Journal of Innovation Management, 14(3): 379-397.

http://dx.doi.org/10.1142/S1363919610002696

Subramaniyam, P., Srinivasan, K., \& Prabaharan, M. 2011. An Innovative Lean Six Sigma Approach for Engineering Design. International Journal of Innovation, Management and Technology, 2(2): 166-170.

Tushman, M. L., \& Nadler, D. A. 1986. Communication and Technical Roles in R\&D Laboratories: An Information Processing Approach. Management of Research and Innovation, 15: 91-111.

Welo, T., Olsen, T. O., \& Gudem, M. 2012. Enhancing Product Innovation through a Customer-Centered, Lean Framework. International Journal of Innovation \& Technology Management, 9(6): 1-28. http://dx.doi.org/10.1142/S0219877012500411

Wilson, K., \& Doz, Y. L. 2011. Agile Innovation: A Footprint Balancing Distance and Immersion. California Management Review, 53(2): 6-26.

Womack, J. P., \& Jones, D. T. 2003. Banish Waste and Create Wealth in Your Corporation. New York, NY: Free Press.

Yamashina, H., Ishida, K., \& Mizuyama, H. 2005. An Innovative Product Development Process for Resolving Fundamental Conflicts. Journal of the Japan Society for Precision Engineering, 71(2): 216-222. 